\title{
Dicționar grotesc
}

\section{Grotesque Dictionary}

\author{
Aluniţa C. Cofan \\ Institutul de Istorie și Teorie Literară „G. Călinescu”, Academia Română, București \\ alunitzacofan@gmail.com
}

\begin{abstract}
A little writing not enough researched and reaching a few pages belonging to Vasile Alecsandri proves the keen interest of a comedies and vaudeville author for language issues, especially for the building of a beautiful and fluent literary language. From our point of view, of a today's researcher, it is the only work published towards the end of the 19th century (approx. 1876), which includes in the title the term of grotesque with certain connotations, unusual for the Romanian cultural space. Through an analysis sourcing in the New Criticism, we will show the links, avant la lettre, with the aesthetics of the grotesque in the Romanian space and the intuitions of a writer, considered "easy", although a classic of Romanian literature.
\end{abstract}

Keywords: linguistic grotesque, aesthetic of grotesque, Vasile Alecsandri, New Criticism, literary language

Pentru cei mai mulți cercetători ai grotescului (Karl Rosenkranz, Wolfang Kaiser, John Ruskin, Mihail Bahtin, Nikolai Hartman, Evanghelos Moutsopoulos, Madeleine Sechter, $\mathrm{Ph}$. Thompson, Harold Bloom), el este o categorie estetică greu de suprins în identitatea ei specifică, fiind o simbioză a formelor și un fenomen estetic de hotar, el este alcătuit din imagini hibride și distorsionate, din entităţi opozitive și contraste ireconciliabile sub raport estetic, cum ar fi frumos și urât, sublim și monstruos, grațios și respingător, comic și urât, burlesc și îngrozitor etc, o contradicție a logicii și a modului de gândire logic, matematic. Abia menționat sub forma „cuțitului fără mâner” sau al „,cvadraturii cercului”, grotescul lingvistic frizează absurdul și inimaginabilul. Oare poate exista un grotesc lingvistic? Poate 
exista un grotesc dincolo de imagini și de înfățisări deformante, înspăimântătoare și atrăgătoare în același timp, ale fanteziei? Iată că se poate și, cazul lui Vasile Alecsandri, nu este singular pentru acreditarea teoriei unui grotesc de limbaj, dar care are alte conotații decât cele cu care ne-au obișnuit cercetători serioși.

Micul op al lui V. Alecsandri, intitulat Dicționar grotesc este publicat între aparițiile mai răsunătoare ale lucrărilor lui Th. Gautier, Les Grotesques (1844), a lui Karl Rozenkranz, O estetică a urâtului (1853) și a lui Hippolyte Taine, La philosophie de l'art (1865) unde termenul de grotesc este statuat specific de fiecare autor în parte. Totuşi, ne interesează mai mult lucrarea lui Th. Gautier, pe care Alecsandri ar fi putut să o cunoască, date fiind desele contacte cu spațiul cultural francez și faptul că primește premiul latinității la Montpellier în 1878 pentru Cântecul gintei latine. În 1856, Théophile Gautier publică o suită de medalioane literare, „mai mult sau mai puțin grotești”, în două volume, Les Grotesques (Editeurs Michel Lévy Frères, Paris). Este o lucrare de istorie și critică literară a cărei miză este acțiunea de recuperare și reevaluare estetică a unor autori de a doua sau a treia mână, disprețuiți sau căzuți în uitare, uneori pe nedrept. Alteori, însă, pe bună dreptate. Cine sunt acești autori? Biograful și criticul Th. Gautier se ocupă de zece astfel de scriitori: François Villon, Scalion de Virbluneau, sieur d'Ofayel, Théophile Viau, călugărul Pierre de Saint Louis, Saint-Amant, Cyrano de Bergerac, Colletet - unul dintre cei patruzeci de la Academie, Jean Chapelain - teoretician al clasicismului francez, Georges de Scudéry, Paul Scarron. Semnificativ este că Th. Gautier aplică termenul de grotesc lipsei de valoare estetică a operelor literare examinate. Din această panoplie negativă a lipsei de valoare estetică, nuanțele de grotesc nu lipsesc: „prostul gus” („mauvais goût” - p. 52), „gunoi” (,le fumier des écrivains de second ordre” - p. 400), ,expresii afectate și de un gust îndoielnic” (de genul concettismului și prețiozității: „piment de concetti et de gongorismes” - p. XII), ,amestec confuz de elemente eteroclite” (,un fatras énorme et indigeste” - p. 286), „platitudini, exagerări și monstruozități ale limbajului” („,cela est monstrueusement nul, démesurément plat et gingantesquement médiocre” - p. 46), „ridicolul și vidul expresiei” („Le ridicule du père Pierre de Saint-Louis, est un ridicule énorme et titanique qui n'admet aucune comparaison" - p. 126), ,arabesc" (însemnând figuri ornamentale grotești, amestec disparat de elemente, stârnind râsul, tipice fanteziei baroce: „Le profil de l'Apollon est d'une grande noblesse; c'est vrai; mais ce mascaron grimaçant, dont l'oeil s'arrondit en prunelle de hibou, dont la barbe se contourne en volutes d'ornements est, à de certaines heures, plus amusant à l'oeil" - p. XI) (Cofan, 2017, pp. 34-35).

Din aceste conotații ale grotescului să reținem câteva, precum „monstruozități ale limbajului”, ,prostul gust”, „vidul expresiei”, pe care le vom regăsi și în încercarea de studiu lingvist a lui Alecsandri. Dar, în timp ce Th. Gautier aplică aceste sentințe valorii literare a unor lucrări de beletristică, deci absenței frumosului, Alecsandri le formulează legat de exprimarea defectuoasă, lipsită de cultură și, mai 
ales, de cultură lingvistică a unor ... „,pedanți” din presa cotidiană sau din anumite lucrări științifice ale vremii.

Ce reprezintă ,,pedantismul” pentru Alecsandri în cadrul unei societăți ,începătoare", cum este societatea română la mijlocul secolului al XIX-lea și pentru care cea mai mare nenorocire este aceea de a „deveni grotesc"? Alecsandri face un fel de operă de asanare, culegând din presa vremii, din diferite poezii publicate de poeții „pedanți” și din discursurile parlamentare structuri lingvistice, sensuri stricate și formulări știrbe, neconforme cu spiritul limbii române. Ei, bine, pedanții secolului al XIX-lea, așa cum apar în gândirea poetului Pastelurilor, sunt lipsiți de orice simț estetic, sunt „cloanțe infernale”, „buhne cobitoare”, sunt, de fapt, snobii din ziua de azi care vor să pară învățați, dar, necunoscând bine propria limbă maternă, nu-și arată decât goliciunea gândirii. Pentru Alecsandri, aceștia poartă semnele „trivialităţii cele mai revoltante” și emit nonșalant „monstruozităţi limbistice”, păcătuind „contra bunului simț ori în contra esteticei și în contra poeticei armonii a graiului român”. Deși numit „dicționar”, totuși cuvintele incriminate și, mai mult ca sigur, întâlnite des de poet, fiindcă i-au stârnit mânia revoltată, nu sunt aşezate în ordine alfabetică, ci în ordinea probabilă a frecvenței lor. Un număr de douăzeci și șase de termeni, plus vreo trei sufixe (substantivale: -ciune, -țiune, -țione; adverbial: -minte) foarte prolifice, câteva sintagme, cu rol de ticuri verbale (ei bine!) și o intejecție (uă!) constituie capetele de acuzare lansate de poet asupra proastei folosiri a limbii române în poezie, presă și discursurile parlamentare. $\mathrm{Nu}$ punem în discuție cât de infailibil este simţul lingvistic al poetului și nici cât este corectitudine și cât eroare din aprecierile lui asupra limbii, privite din perspectiva secolului al XXI-lea, ci doar vrem să arătăm modul de a proceda asupra materialului lingvistisc strâns de poet și legăturile afirmațiilor sale cu estetica grotescului, afirmată din plin în secolul următor.

Așadar, există un număr de douăzeci și șase de termeni glosaţi de Alecsandri, după cum urmează: onoare (în loc de *onor), pudoare (în loc de *rușinie), amoare (în loc de amor), amare (în loc de a iubi), beleță (în loc de frumusețe), inimici (în loc de dușmani, neprieteni), lăcrimoare (cu sensul de 'lacrimi mici'), poezii noi, redaptor (de fapt redactor), rumân (în loc de român), vergură (în loc de virgină), animă (cu adjectivul derivat animal), a incinge (sensul criticat fiind 'a lua foc'), garanță (confundată cu garanția, sensul de bază fiind 'un material din care se fabrică culoarea roșie'), prospect (în loc aspect), văzută (în loc de vizită), tinută (cu variantele contextuale: mare ținută, ținută de paradă, ținută de gală; dar nu ni se spune și ce variantă se propune pentru acest termen), tele și sele (în loc de tale și sale), ered (în loc de moștenitor), negles (în loc de neglijat, Alecsandri zice negligeat), regres (în loc de regret sau regretare), morb (cu variantele: morbos, morboasă, morboși; pentru bolnav, boală), resbel (în loc de război), popul (în loc de popor), președinte (în loc de *prezident), ședință (în loc de *seanță). La o primă analiză, cuvintele incriminate de Alecsandri sunt neologismele din limba franceză, 
limba latină și limba italiană (cele cu sufixul -țione) adoptate de „pedanți” fără simţul lingvistic evolutiv al limbii române și obținând un efect comic și grotesc (rizibil, urât și ininteligibil) în planul comunicării. Țintele criticii sale sunt mai ales reprezentanții latiniștilor transilvăneni (Timotei Cipariu, Simion Bărnuțiu) care doreau reîntoarcerea limbii române la formele lexicale din limba latină, considerată de aceștia ca certificatul de noblețe al limbii române. Desfigurarea cuvintelor și a sensurilor, cacofoniile, schimbarea genului gramatical, năvala sufixelor în -țiune care s-au înstăpânit în ziaristica vremii și în elocvența paralamentară sunt motivele furiei poetului în acest glosar de termeni din secolul al XIX-lea. Este evident că, în unele cazuri, simțul lingvistic al lui Alecsandri a dat greș, zeflemisând ca incorecte cuvinte păstrate în limbă precum ținută, pudoare, ședință, președinte, onoare și intrate azi în norma exprimării corecte. Totuși, nu ne interesează prea mult raportul dintre eroare și corectitudine sub aspect lingvistic, ci mai mult conotaţiile limbajului botezat „grotesc" și legăturile acestora cu estetica categoriei. Să observăm mecanismul de luare în râs și acoperire de ridicol pe care-l utilizează glosatorul. Alecsandri procedează la situarea într-un context ridicol și rizibil al termenului vizat, mizând pe alunecări de sens provenite din omofonii, iar apoi la zeflemisirea termenului pus într-un alt context din care se obțin sensuri monstruoase, total aberante, neuitând să facă jocuri de cuvinte ironice și calambururi sarcastice. Să luăm, de exemplu, substantivul beleță din care poetul derivă ludic și verbul belește (cu sensul de 'înfrumusețează'), inventând versuri ad-hoc în care s-ar putea exprima un poet susținător înfocat al latiniștilor ardeleni:

Frumuseță pedantescă! Închipuiască-și fiecine efectul ce ar produce asupra unei dame delicate o strofă ca aceasta:

Ah! Doamnă, ești belă ca roza ce crește,

Și fruntea-ți divină treptat se belește!

Ah! Lasă-mă a-ți spune cât sum fericit,

Văzând dulcea-ți față c-astfel s-a belit!

Iată una din cele mai bele flori din estetica pedanților. Tot acestora sîntem datori cu belele-arte și cu foile beletristice. Sărmană limbă, în ce belele ai căzut cu Trisotinii carii te belesc astfel!

Schematizând modul de a proceda al poetului, avem, în exemplul de mai sus: ironia (,frumuseță pedantescă” prin care lasă să se înțeleagă tocmai pe dos, deoarece știm că termenul pedant este încărcat de conotații negative); ilustrarea aberațiilor de sens prin contaminări omofonice; alte exemple negative de cuvinte compuse (în treacăt fie spus, Alecsandri aici greșeste) și referința livrescă la personajul lui Molière din Les femmes savantes, Trissotin. Personajul lui Molière este expresia prin excelenţă a pedantului, în viziunea lui Alecsandri, caracterizat prin: logoree verbală, îngâmfare cognitivă, ipocrizie, fals erudit și incompetent în chestiuni de limbă.

$\mathrm{O}$ altă intrare din glosarul lui Alecsandri este termenul amoare în loc de amor. Traseul este: precizarea termenului corect, schimbarea genului gramatical, referință 
mitologică, comicul omofonic și ilustrarea ridiculizantă (din care nu lipsește, bineînțeles, săgeata zeflemisitoare la adresa lingviștilor ardeleni). Iată exemplificarea:

În loc de amor, precum onoare în loc de onor; iarăși o schimbare de sex. Zeul Cupidon nu mai e băiet înarmat cu tolbă de săgeți, ci o fetică la gherghef. Pedanții nu mai respectează nimic în lume, nici chiar mitologia! Ei ar merita soarta lui Acteon. Amoare are pe lângă multele dezavantaje și acela de a raporta gândul la postul Crăciunului şi a supăra delicateța mirosului. Un băiet de peste Carpați a zis:

Amantul tău ferice, la tine vrând să zboare,

În aer vede, sîmte și mirosă a moare!

Să observăm că, din punctul de vedere al teoriei lingvistice asupra formării cuvintelor, Alecsandri adoptă o atitudine democratică (spre deosebire de vederea îngustă și perimată a latiniștilor transilvăneni): preferă păstrarea termenului de origine slavă (cum este în cazul lui amare și $a$ iubi), înclină spre cuvântul latinesc mai vechi (frumusețe derivat din formosus și nu beleță care constiuie o inovație mai târzie în latina vulgară, conform observaților lui Eugen Coșeriu din studiul Limba română - limbă romanică, unde afirmă că inovațiile lexicale pornite din centrul peninsulei italice au ajuns cu greu sau deloc în marginea imperiului, Dacia, Peninsula Iberică, care au păstrat forme mai vechi din latina vorbită); compară termenul românesc cu cel existent în celelalte limbi romanice, franceza, spaniola, italiana, pentru fixarea termenului corect (ceea ce recomandă și E. Coșeriu pentru lingviștii de după cel de-al doilea război mondial: cunoașterea tuturor limbilor romanice și a tuturor limbilor slave, nu numai a francezei moderne!), recomandă termenul popular, încredinţat fiind de bunul-simț și judecata dreaptă a poporului în materie de limbă (în loc de neologismul pudoare reține termenul popular ruşinie).

Stăpânind bine articulațiile limbii române și ale comicului, iată cum este introdus cuvântul amare în glosar:

Amare - a iubi! Un cuvânt inutil și care produce conjugări comice; de pildă:

Eu am! În loc de eu iubesc, este un calambur grotesc.

Eu te am, doamnă! În loc de eu te iubesc, doamnă! Este o impertinență care expune pe nenorocitul pedant a fi dat afară cu amoru-i cu tot; însă ce-i pasă pedantului! Nu-i rămâne gramatica drept mângâiere? El o strânge la pept cu amoare și-i zice: Tu, fidela mea consoartă, ești universul meu! Te am, te-am amat, te amai, te amam, te voi ama, ama-te-voi etc.

Amorul spăriet își astupă urechile şi fuge.

În fine, cel mai lung articol din acest glosar este cel consacrat termenului onoare, primul din capul listei de douăzeci și șase de intrări lingvistice. Îl cităm integral nu atât pentru desfătarea umoristică, cât mai ales pentru a remarca direct modul cum procedează poetul, marota centrală a criticii sale fiind ,frumusețea limbii şi armonia sunetelor”. Iar grotescul este tot ce poate fi mai dizarmonic, mai monstruos, mai desfigurator! Să citim articolul de glosar: 
La toate popoarele de sânge sau de rudire latină, acest sentiment are un carcater de bărbăție și este exprimat prin cuvinte de soi masculin.

Latinul zice honor.

Francezul zice l'honneur.

Italianul - l'onore.

Spaniolul - el honor.

Era deci foarte logic și foarte natural ca și românul să zică onor; însă nu; căci pedanții au găsit de cuviință... gramaticală a schimba sexul acestui sentiment de demnitate energică, a-i da o natură muieratică, a-l înfățișa în poale lungi și a-l boteza onoare. Urmând astfel voit-au oare să facă un act de grațiozitate cătră sexul frumos? Nicidecum, pentru că nu sunt aprețiatorii frumuseței și armoniei; ei nu au altă credință, alt Dumnezeu pe lume decât sistemul gramatico-filologico-etimologico-ablativo-burlesco etc., la care se închină orbește ca bonzii din India în numele lui Vișnu.

Iată dar cel mai important dintre cuvintele nouă-române desfigurat! De aceea auzi pe mulți adăugând la toată fraza: pe onoarea mea! precum mai-nainte cei carii își băteau joc de lege ziceau: pre legea mea! Acest jurământ, atât de sacru în gura unui om onorabil, a devenit o formulă uşoară și comodă, care servea de umplutura frazelor celor mai seci. Am auzit la București următor frgment de convorbire:

- Ticălosul! A îndrăznit, mon cher, să-mi deie o palmă!

- O palmă!... Ți-a dat o palmă? Nu se poate.

- Pe onoarea mea, nene!... m-a pălmuit.

Cuvântul onoare este pluralul cuvântului onor, precum popoare pluralul lui popor, topoare, topor etc. El are deci înțelesul de măriri, ranguri, avantagele unei poziții înalte, lucruri ce se dobândesc adeseori cu sacrificiul onorului, adică a demnităței personale. Francezul zice:

Vous briguez les honneurs aux dépens de l'honneur.

Alergând după onoare, perzi adesea onorul tău.

A zice dar onoare, în loc de onor, este o probă de corumpere morală într-o societate; căci onoarele se câștigă chiar și prin înjosire, când onorul e un ce sacru, care se naște cu omul, se dezvoltă cu îngrijirea educației și niciodată nu se poate înfrăți cu înjosirea.

Armata română a luat ca deviză cuvintele onoare și patrie (honneurs et patrie!) deviză greşită; căci ea pune onoarele, adică avantajele rangurilor, înaintea patriei. Ar fi de demnitatea armatei ca să dea pasul patriei și să înscrie pe stindardele sale: Patrie şi onor!

În fine, atâtea acte dezonorabile s-au comis în România sub regimul onoarei, că pentru a păși într-o eră mai demnă de numele ce purtăm, e timpul să ne lepădăm de onoare și să ne înfrățim cu onorul.

Evident, Alecsandri încearcă înfrățirea limbii române cu celelalte limbi ale „gintei latine” și cu strămoaşa tuturor acestor limbi, latina; el care, în general, se declară contra formei latinizante. Pentru a menține genul masculin al cuvântului onor (păstrat până azi în terminologia militară în expresia a da onorul = a saluta, dar a rămas onoarea militară și deviza onoare și patrie și a fi îngropat cu onoruri militare) ce reprezintă pentru el virilitatea și masculinitatea (bărbații fiind singurii 
care au onoare, pardon!, onor), el face un paralelism (greșit) cu forme lexicale similare din limba română precum topor și popor și, după o scurtă trimitere la o zicală franțuzeacă (tradusă mai exact prin: căutați onorurile în detrimentul onoarei), face o analiză socială a corupției morale, din pricina proastei înțelegeri a diferențelor de sens dintre onoare (de fapt: onoruri) și onor (azi: onoare), oprindu-se, în final, la lexicul militar unde funcționează încă deviza onoare și patrie (recomandarea poetului fiind schimbarea acestei devize în onor și patrie, deoarece, după el, onoare e forma de plural cu semnificația de 'ranguri, avuții, avantaje materiale').

Mai trebuie să băgăm de seamă că sufixele substantivale (-ciune, -țiune, -țione) erau în mare vogă în vremea lui Alecsandri. Pe acestea, poetul le exilează în zona aberațiilor lexicale (,aberăciune”, zice el în derâdere), iar pe cei care le folosesc din abundență îi numește „,ciuniști” sau ,țiuniști”, în funcție de sufixul ales de vorbitor. Poetul alege două exemple. Primul al unui ,june țiunist” care:

ar căuta să înduioșeze pe îngerul adorărei sale, zicându-i cu glas tremurător: Ah! doamnă, aparițiunea d-voastră mă aduce într-o emoțiune... mă pătrunde de o senzațiune... mă pune într-o confuziune, cât nu pot să vă fac o declarațiune demnă de... etc, etc. Îngerul și-ar freca urechile cu mânile trandafirii şi ar cădea numaidecât în spasmuri.

Al doilea exemplu este luat din discursurile parlamentare:

Camera deputaţilor și Senatul răsună adeseori de țiuituri și mai accentuate. De pildă: Domnilor! Cestiunea a dat loc la multe discuțiuni în secțiuni și la multe interpelațiuni asupra intepretațiunei constituțiunei. Protestațiunile majorităței au produs adânca senzațiune în sânul reprezentațiunei naționale și ele au cauzat frecuente intrerupțiuni în discuțiunea propozițiunei ministeriale... etc., etc. Ar jura fiecine că asistă la glumele flăcăilor de țară în nopțile de șăzători și că aude o limbă păsărească. Să fie oare Camera o șăzătoare?

Năvala acestor sufixe în texte poetice și discursuri, distrugând armonia limbii române și multiplicând termenii disonanți (la care urechea lui Alecsandri era foarte sensibilă), nu a putut fi oprită, poate doar un pic redusă, din moment ce, peste vreo șaptezeci de ani, T. Arghezi ia în bătaie de joc același mod de exprimare cu ,țiuni” în mozaicul de proze antiutopiste Tablete din Țara de Kuty (1933). Ataşate cuvintelor banale, ele au aerul de-a le da un aspect de noutate elitistă şi savantă, dar în realitate, nu fac decât să le golească de conţinut:

[...] pentru a intra în mişcarea militantă, prima condiţiune nu este numai să fii versat în complicaţiunile Constituţiunii, dar făcând chiar excluziune de această condiţiune, dar o imperioasă datorie îţi dă obligaţiunea [...]. Nefiind un ce vulgar, politica subînţelege o educaţiune, şi numai terminaţiunea, indiferent de observaţiune, permite o justă operaţiune (Ministrul, pp. 122-123).

Arghezi însuşi acoperă de sarcasm gargariseala pompoasă şi pretenţioasă a oratorilor politici, ce, din dorinţa de epatare a publicului elector folosesc anapoda, 
neconform cu spiritul limbii, sufixe sonore ca -ţiune, -iţie, -iziune. Așa se întâlnesc peste timp două spirite din arborescenta familie a scriitorilor români, preocupați de dereglarea limbajului și, deci, de îmbolnăvirea gândirii. Grotescul lingvistic, care indică persistenţa în imaginaţie sau ficţiune a unei „fiinţe verbale aberante” şi redă impasuri ori dileme ale gândirii logice, precum „cercul pătrat” al lui Leibniz sau „cuţitul fără lamă căruia îi lipseşte mânerul” al lui Lichtenberg. Așadar, dereglarea și stricarea limbajului corespunde, în genere, unei îmbolnăviri a lumii (datorate îndeosebi absenţei unei supraordonări morale) şi unor maladii ale gândirii („Somnul raţiunii naşte monştri”, spunea Goya). Temă exploatată şi de Eugen Ionescu în piesele sale, începând cu Cântăreața cheală. Grotescul este tot ceea ce poate fi mai iraţional sau ilogic, aberant, straniu şi anormal. Obişnuitele tipare ale percepţiei sunt depăşite şi e nevoie de o sensibilitate halucinantă, de genul celei promulgate de Rimbaud prin „dereglarea tuturor simţurilor”, ce permite „ex-stazul”, ieşirea în afara tiparelor raţionale, delimitate logic, o investigare a lucrurilor imperceptibile în mod normal (Cofan, 2017, pp. 127-128).

Extrem de modern în gândire, Alecsandri lasă grotescul să evolueze, să-şi schimbe fațetele într-o serie de relații contextuale din care să reiasă cu claritate trăsăturile sale estetice. Pe cât se vede el este definit ,pe contra” și formându-se dintr-o lungă listă de absențe și negativități: contra frumosului, lipsă de simț estetic, monstruozități „limbistice”, contra bunului simţ, contra esteticei, contra poeticei armonii. A fi grotesc este o nenorocire, este o calamitate și lingvistic vorbind „o bâiguială ridicolă”, o „limbă păsărească”, „un galimatias” nepăcut și respingător. Neînsușirea corectă a proprietății termenilor și a sensurilor exacte cauzează numeroase greșeli, zice poetul: „lapsus linguae” și barbarisme. Toate aceste conotaţii sunt însă dominate de trasătura „neinteligibilului”, a ,ilogicului” și ,,absurdului”. Făcând o statistică a recurenței ca atare a termenului grotesc de-al lungul acestei scurte scrieri, ea indică, fără dubii, că Alecsandri îi cunoștea foarte bine sensurile și îl utiliza în cunoștință de cauză. Personajul din imaginarul literaturii care se încadrează cel mai bine în utilizarea unui limbaj dereglat, a verbiozității, a ilogismelor, a confuziilor și contradicțiilor logice în exprimare, a exprimării hiperbolice (multiplicarea haotică a sensurilor) este Trissotin care crezându-se deasupra tuturor și nefiind decât o ființă calpă, crezându-se plin și fiind gol, face trecerea dintre limbajul grotesc și imaginarul grotesc.

Iar noi am fi putut la fel de bine numi această lucrare „dicţionar trissotin” sau „despre trissotinism”. 


\section{BIBLIOGRAFIE}

Alecsandri, V. (1984). Dicționar grotesc. In Dridri (proză). Vol. 2. București: Editura Minerva.

Arghezi, T. (1967). Tablete din Țara de Kuty. In Scrieri. Vol. 14. București: Editura pentru Literatură.

Bahtin, M. (1982). Probleme de literatură și estetică. București: Editura Univers.

Bloom, H. (ed.) (2009). The Grotesque. New York: Bloom's Literary Criticism.

Cofan, A.C. (2017). Estetica și hermeneutica grotescului. București: Editura Tracus Arte.

Coșeriu, E. (2005). Limba română - limbă romanică. București: Editura Academiei Române.

Hartman, N. (1974). Estetica. București: Editura Univers.

Kaiser, W. (1966). The Grotesque in Art and Literature. New York / Toronto: McGraw-Hill Book Company.

Kaiser, W. (1979). Opera literară. București: Editura Univers.

Moutopoulos, E. (1976). Categoriile estetice (introducere la o axiologie a obiectului estetic). București: Editura Univers.

Rosenkranz, K. (1984). O estetică a urâtului. București: Editura Minerva.

Ruskin, J. (2010). Groteque Renaissance (Chapt. III). In The Stones of Venice. Vol. The works of John Ruskin. Cambridge: Cambridge University Press.

Thomson, Ph. (1972). The Grotesque. London: Methuen. 